\title{
Ischemic postconditioning may not influence early brain injury induced by focal cerebral ischemia/reperfusion in rats
}

\author{
Yoo Kyung Kim, Jeong Gill Leem, Jin Woo Shin, and Kyoung Woon Joung \\ Department of Anesthesiology and Pain Medicine, Asan Medical Center, University of Ulsan College of Medicine, Seoul, Korea
}

Background: Experimental studies have shown that ischemic postconditioning can reduce neuronal injury in the setting of cerebral ischemia, but the mechanisms are not yet clearly elucidated. This study was conducted to determine whether ischemic postconditioning can alter expression of heat shock protein 70 and reduce acute phase neuronal injury in rats subjected to transient focal cerebral ischemia/reperfusion.

Methods: Focal cerebral ischemia was induced by intraluminal middle cerebral artery occlusion for $60 \mathrm{~min}$ in twenty male Sprague-Dawley rats (250-300 g). Rats were randomized into control group and an ischemic postconditioning group (10 rats per group). The animals of control group had no intervention either before or after MCA occlusion. Ischemic postconditioning was elicited by 3 cycles of $30 \mathrm{~s}$ reperfusion interspersed by $10 \mathrm{~s}$ ischemia immediately after onset of reperfusion. The infarct ratios, brain edema ratios and motor behavior deficits were analyzed $24 \mathrm{hrs}$ after ischemic insult. Caspase-3 reactive cells and cells showing heat shock protein 70 activity were counted in the caudoputamen and frontoparietal cortex.

Results: Ischemic postconditiong did not reduce infarct size and brain edema ratios compared to control group. Neurologic scores were not significantly different between groups. The number of caspase-3 reactive cells in the ischemic postconditioning group was not significantly different than the value of the control group in the caudoputamen and frontoparietal cortex. The number of cells showing heat shock protein 70 activity was not significantly different than the control group, as well.

Conclusions: These results suggest that ischemic postconditioning may not influence the early brain damage induced by focal cerebral ischemia in rats. (Korean J Anesthesiol 2010; 58: 176-183)

Key Words: Focal cerebral ischemia, Neuroproctection, Postconditioning, Rat.

Received: May 25, 2009. Revised: 1st, June 28, 2009; 2nd, July 12, 2009. Accepted: August 3, 2009.

Corresponding author: Jeong Gill Leem, M.D., Department of Anesthesiology and Pain Medicine, Asan Medical Center, University of Ulsan College of Medicine, 388-1, Pungnap-dong, Songpa-gu, Seoul 138-040, Korea. Tel: 82-2-3010-3861, Fax: 82-2-470-1363, E-mail: jgleem@amc.seoul.kr (c)This is an open-access article distributed under the terms of the Creative Commons Attribution Non-Commercial License (http:// creativecommons.org/licenses/by-nc/3.0/), which permits unrestricted non-commercial use, distribution, and reproduction in any medium, provided the original work is properly cited. 


\section{Introduction}

Brain damage followed by cerebral infarction cause deformity/ destruction of brain constantly even after reperfusion of cerebral blood flow was done. The opening of blocked blood flow as one of treatments for cerebral infarction can cause $2^{\text {nd }}$ damage by damaging reperfusion which produces active oxygen and free radicals [1]. So, even numbers of studies about medicines or treatments to reduce destruction of brain cell have been done, but there have been yet no surely verified treatments. Ischemic preconditioning by means of repeated treatments of intermittent block of blood flow and reopening suggested by Murry et al. [2], was known as a treatment to operate strong intrinsic suppressive mechanism for prevention damage of ischemia organs, but since it can be limitedly applied only under situation that ischemia may be predicted theoretically, it has limitation in applying that it should be done clinically in extremely limited situation. Recently, it was reported first by Zhao et al. [3] that ischemic postconditioning performed on heart of experiment $\mathrm{dog}$, that is, repeated treatments of intermittent block of blood flow and reopening for short time direct after ischemia, has similar prevention effect to ischemic preconditioning for myocardial necrosis after reperfusion. Relating to cerebral blood flow, Zhao at al. [4] presented that intermittent block of blood flow in reperfusion result in significant reduction of brain damage after brain ischemia/reperfusion locally in Rat, and suggested treatment method for cerebral infarction. However, even though numbers of studies have been performed, exact suppressive mechanism has not been yet found. It is significant meaning in that Postconditioning can be applied after ischemia compared to preconditioning.

Heat shock protein (Hsp) is a protein which can make cells to cope with stress that cause harmful stimulus and environmental damage [5], and also restrain deformity of protein and reduce inflammatory response, and have cytoprotective effects for reducing cell necrosis and apoptosis [6]. Hsp70 has been recognized to be increased relating to brain ischemia [7], and lot of efforts has been made to reduce brain damage by increasing expression of Hsp [8]. Regarding relevance between Hsp 70 and neuroprotective effect, there are increasingly reported recently $[9,10]$, but unfortunately mostly studied in only limited specific model and also didn't clarify clearly not only about causal relationship with ischemic postconditioning but also about proper cycle and time to appear neuroprotective effect and reperfusion method. The purpose of this study is to review whether effect of brain protection is or not, degree of the effect, and influence on expression of Hsp 70 which are appeared by hemispatial ischemical postconditioning in local brain ischemia/reperfusion which make reperfusion by inducing ischemia phase after blocking middle cerebral artery (MCA) of Rat.

\section{Materials and Methods}

\section{Ischemia/reperfusion in middle cerebral artery (MCA)}

All animal experiment has been performed under permit of animal experiment ethics committee and also has complied with animal care policy of committee. Using 20 male rats of Sprague Dawley weighing 250-300 gr, they was fed by water and prey normally at the interval of 12 hours until experiment day in breeding room equipped with dimmer. Experiment animals were classified at random into Controls group and ischemic postconditioning group having 10 rats respectively. Experimental rats were injected zoletil $12.5 \mathrm{mg}$ and xylazine $3 \mathrm{mg}$ into abdominal cavity, and then removing fur around neck and fixing them in supine position at animal guides, putting clinical thermometer inside rectum, keeping their body heat $36.5^{\circ} \mathrm{C}$ using heating pad, and keep their spontaneous breathing properly during operation.

Operation method of middle cerebral artery occlusion referred to previously reported method [11]. Rods in $400 \mu \mathrm{m}$ thick were made by heating 4-0 nylon monofilament (Johnson \& Johnson, USA). Performing midline incision at cervical region, and then after desquamating ambient thyroid, nerves, and fascia under dissecting microscope, common carotid artery in both side were found and left common carotid artery was exposed to branch point between internal carotid artery and external carotid artery. Distal portion of external carotid artery and internal carotid artery was tied up loosely and after holding common carotid artery with curved microvascular clip, and then incise external carotid artery, 4-0 nylon monofilament rod was inserted inside internal carotid artery around $20-21 \mathrm{~mm}$ depth until feeling of resistance.

After operation of middle cerebral artery of control group, ischemia happened for 60 minutes, and so, put forceps on left common carotid artery for that time, and then after 60 minutes, pull 4-0 nylon monofilament rod outside so as not to break external carotid artery, take off clip in common carotid artery, and finally reperfuse middle cerebral artery. For postconditioning group, after inducing them for ischemia in same environment with control group, and then pull nylon thread out to branch point of common carotid artery and release clip in left common carotid artery for 30 seconds to reperfuse and to induce ischemia again. Reperfusion and Ischemia were repeated in 3 times in same way. Experiment animals were moved to breeding room after coming out of anesthetic followed by removal of nylon thread and suture the skin

\section{Measurement of neurological score}

After 24 hours since brain damage, neurological score of rat 
was measured. In neurological scores, score 0 was in case of normal, score 1 was in case if forelegs were bent on hang up rat by tail, score 2 was in case if gripping force of forelegs was reduced, score 3 was in case that it can move to any direction but when was pulled up by tail, it turn to opposite side, and lastly, score 4 was in case if it turn to opposite side even in remaining quiet with nothing [12].

\section{Measurement of infarction areas and observation of cerebral edema}

After measuring neurological score and anesthetizing using zoletil $12.5 \mathrm{mg}$ and xylazine $3 \mathrm{mg}$, decapitation was done and brain was extracted. Extracted brain was also amputated along observing surface towards frontal lobe from branch point of middle cerebral artery at the interval of $2 \mathrm{~mm}$, and then amputated tissue dyed in 2\% 2,3,5-triphenyltetrazolium chloride (TTC, Sigma, USA) which was dissolved in saline solution at $37^{\circ} \mathrm{C}$ for 30 minutes, and was fixed at $4^{\circ} \mathrm{C}$ by phosphatebuffered formaline. Infarct area was not dyed and was shown in white similar to existing brain tissue, while normal tissue became dyed in red. Total area of infarct area was analyzed by image analysis system (Image I software, NIH, USA), and ratio of infarction was converted total area of ipsilateral cerebral hemisphere divide by infracted area [13], cerebral edema formation ratio of infracted area was calculated by area ratio of both cerebral hemisphere inside same amputated surface [14].

\section{Immunohistochemical analysis}

After making paraffin cake in $4 \mu \mathrm{m}$ thick from infracted area of each groups and brain tissue of object in which cerebral edema was observed 24 hours later from brain damage, deparaffinizing it using xylen and dehydrate it by ethanol and distilled water step by step, and then activity of caspase-3 and activity of Hsp 70 was investigated in immunohistochemical method.

To investigate activity of caspase-3, commercialized kit (Sigma Statin ${ }^{\circledR}$ Cleaved Caspase-3 (Asp 175) IHC kit, cell signaling technology, USA) was used. After dropping blocking solution on tissue cake, it was treated with primary antibody and negative control, and then it was washed out with phosphate buffered saline (PBS) 24 hours later. Biotinylated secondary antibody was dropped on slide and then 30 minutes later after that, it was washed out with $\mathrm{PBS}$, and $\mathrm{AB}$ reagent which was made by blending reagent $\mathrm{A}$ and $\mathrm{B}$ was dropped on this. After dropping substrate-chromagen which was made by blending ready-made substrate with distilled water on slide, waited until it become reddish brown. And then contrast dye was performed using hematoxylin. Since that, it was dehydrated using xylene and it was fixed with fixatives.
Immunohistochemical analysis of Hsp70 was performed by diluting Hsp70 antibody (HSP70 Antibody \#4872, cell signaling technology, USA) in $1: 50$. For Antigen unmasking, tissue slide was soaked into $10 \mathrm{mM}$ of sodium citrate buffer ( $\mathrm{pH}$ 6.0) and was boiled for 10 minutes and then was cooled down. Tissue slide is applied to $3 \%$ hydrogen peroxide for 10 minutes and washed out by distilled water and tris buffered saline (TBS) $/ 0.1 \%$ Tween-20 (TBS), and then blocking solution which was made by blending normal goat serum with TBST was dropped on it to be applied to room temperature for 1 hour, and treating primary antibody to it and applying it for 24 hours at $4^{\circ} \mathrm{C}$. Since then, it was washed out by TBST and AB reagent was dropped on it. After substrate-chromagen was dropped on slide, contrast dye was performed using hematoxylin. Since then, it was dehydrated by ethanol and xylem and was fixed, and permanent mounting medium was dropped on it and was covered by cover glass.

After number of active cell of caspase-3 and Hsp70 was observed and measured in optical microscope of 400 times magnification selecting 3 places by every $1 \mathrm{~mm} 2$ at hemispheric frontoparietal cortex (boundary zone of local ischemia) and caudoputamen (central zone of local ischemia) in which local ischemia/reperfusion were performed, the median number was taken.

\section{Statistical processing}

Result value was presented in the median number (a quartile). Comparison of morality rate and score of neurological score between the control group and the experiment group was conducted in Chi-square and Fisher's exact test, and area of infarction and edema, number of active cell of caspase- 3 and Hsp70 were analyzed using Wilcoxon rank sum test or Mannwhitney rank sum test. Sigma stat (version 3.1, Stat software, USA) was used for statistic analysis, and it was found to be significant when $\mathrm{P}$ value was less than 0.05 .

\section{Results}

\section{Mortality rate}

There was no died object in both the control group and the ischemic postconditioning group until 24 hours later after brain damage.

\section{Neurological score}

Neurological score which had been observed 24 hours later after brain damage showed score 0 in 5 rats among 10 rats and score 1 in other 5 rats of the control group, while showing same 
score distribution in ischemic postconditioning. No differences were found between two groups.

\section{Comparison of formation degree of cerebral infarc- tion and edema}

There was no difference between the control group and the ischemic postconditioning group in formation rate of cerebral infarction and edema (Fig. 1)

\section{Comparison of number of active cell of Caspase- 3 and Hsp70}

There was no difference in number of active cells in Caspase-3 at both frontoparietal cortex and caudoputamen between the control group and the ischemic postconditioning group 24 hours later since brain damage (Fig. 2, 3, 4).

While in number of active cells of Hsp70, there was no difference at both frontoparietal cortex and caudoputamen between the control group and the ischemic postconditioning group 24 hours later since brain damage (Fig. 3, 4).

\section{Discussion}

Ischemic postconditioning, which was performed in way of that reperfusion of ipsilateral common carotid artery for 30 seconds after ischemia of unilateral middle cerebral artery for 60 minutes and blockage for 10 seconds in consecutively 3 times,
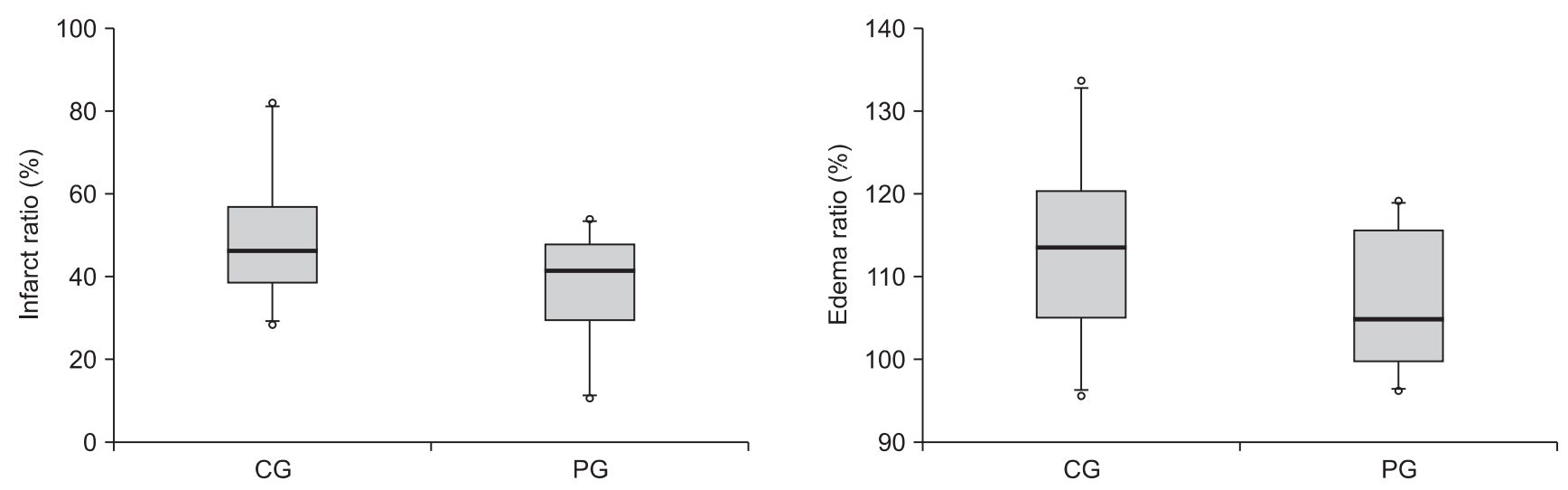

Fig. 1. Infarct ratios and edema ratios, measured at 24 hours after cerebral ischemia/reperfusion injury. Infarct ratios are calculated as the percentage of the size of the infarcted tissue area/ipsilateral hemisphere. Edema ratios are calculated as the percentage of the size of the ischemic hemisphere/contralateral normal hemisphere. The boxes show interquatile ranges; thick lines are medians and error bars are $10^{\text {th }}$ and $90^{\text {th }}$ percentiles. There are no significant differences between the groups. ॰: Extreme cases over 3 times of each box value. CG: control group, PG: ischemic postconditioning group.

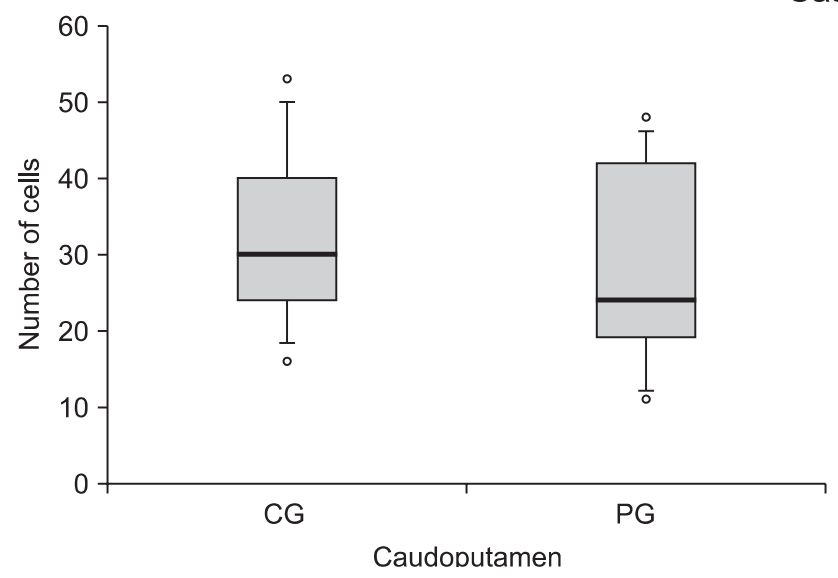

Caspase-3

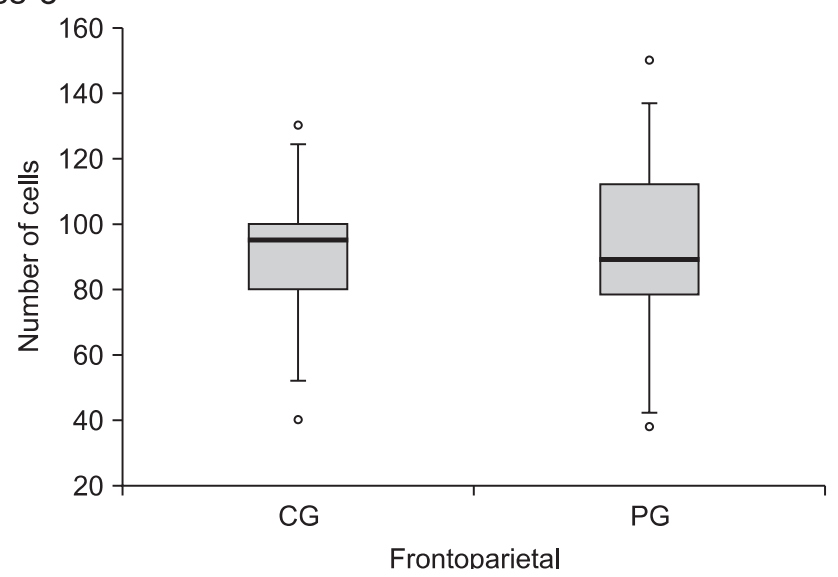

Fig. 2. The number of caspase-3 reactive cells at the caudoputamen and the frontoparietal cortex following cerebral ischemia/reperfusion injury. The boxes are interquatile ranges; thick lines are medians and error bars are $10^{\text {th }}$ and $90^{\text {th }}$ percentiles. There are no significant differences between the groups. ॰: Extreme cases over 3 times of each box value. CG: control group, PG: ischemic postconditioning group. 

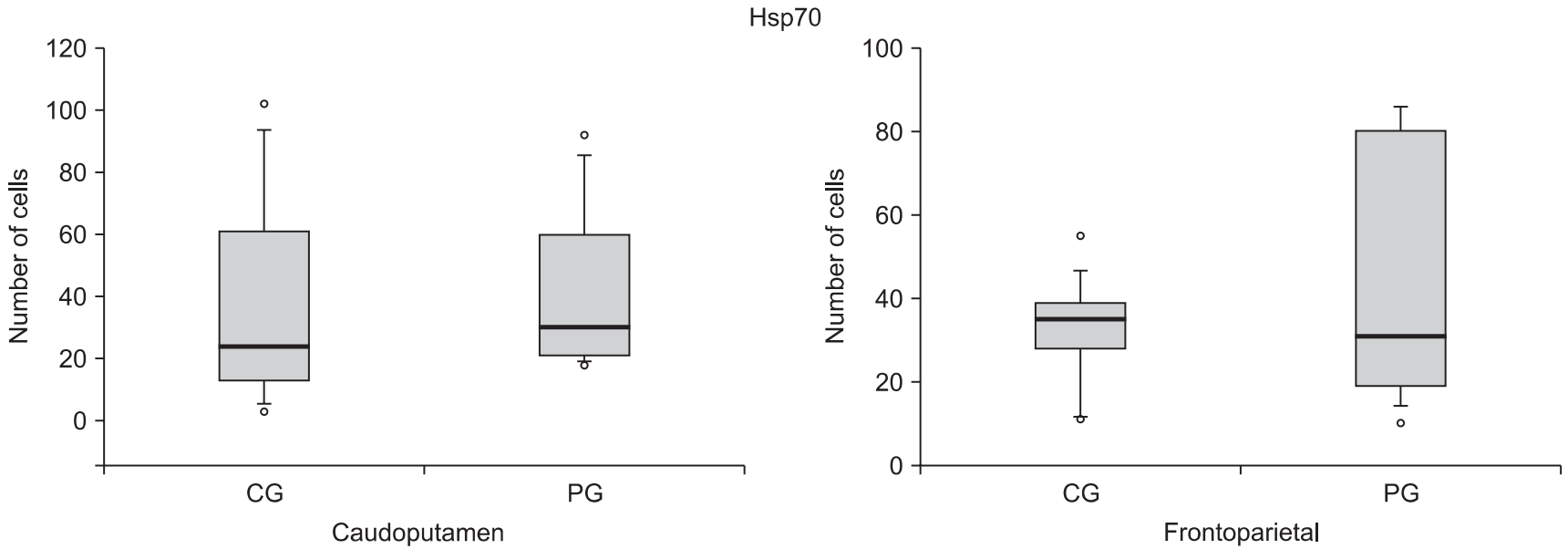

Fig. 3. The number of Hsp70 reactive cells at the caudoputamen and the frontoparietal cortex following cerebral ischemia/reperfusion injury. The boxes are interquatile ranges; thick lines are medians and error bars are $10^{\text {th }}$ and $90^{\text {th }}$ percentiles. There are no significant differences between the groups. o: Extreme cases over 3 times of each box value. CG: control group, PG: ischemic postconditioning group.
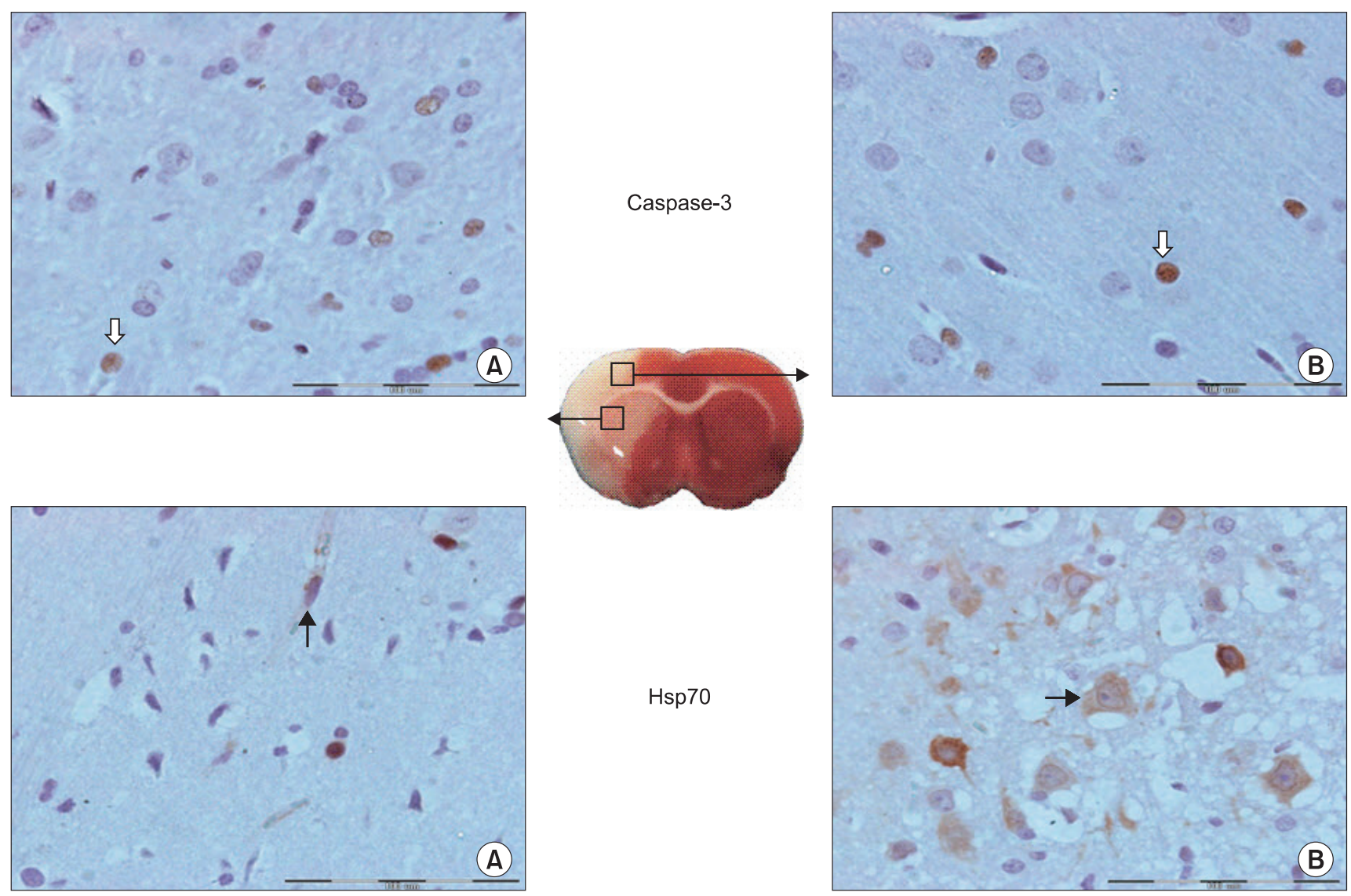

Fig. 4. Representative microscopic images of caspase-3 and Hsp70 reactive cells following cerebral ischemia/reperfusion injury. Cells are measured in the two regions of the ischemic hemisphere: in the caudoputamen (A) and the frontoparietal cortex (B). Caspase-3 reactive (white arrow) and Hsp70 reactive (black arrow) cells are shown. The boxes show $400 \times$ magnification. Scale bar $=100 \mu \mathrm{m}$ in the insets. 
didn't reduce early brain damage after local brain ischemia/ reperfusion. Also in comparison of apoptosis and expression of Hsp70 through immunohistochemical dye, there was no significant difference from the control group. In particular, number of active cell of caspase-3 and Hsp70 were not different from the control group in both central area and ambient area of ischemia respectively. It meant that neuroprotective effect of ischemic postconditioning could not be expected in early brain damage, since it may not induce reduction of nerve damage by apoptosis and increase of Hsp70.

The period of reperfusion after ischemia is very important in pathophsiological mechanism in which damage was caused. It has been known that in the mechanism of brain damage due to cerebral ischemia and reperfusion, there are the damage of ischemia/reperfusion [15], mechanism of cell necrosis [16], the mechanism of apoptosis related to cytochrome $\mathrm{C}$ and caspase- 3 [17], the mechanism of mitogen-activated protein kinase [18], the mechanism of protein kinase C [19], the mechanism of Akt [20]. Ischemic postconditioning, which was regarded as one of mechanisms to have something with cerebral protective effects among mechanisms due to damage of cerebral ischemia/ reperfusion, has been known to reduce death of nerve cell by restraining apoptosis. However, according to previous researches, in a partial reperfusion model in which firstly middle cerebral artery was permanently blocked and then both sided common carotid artery was temporarily blocked, and then reperfuse it, when ischemic postconditioning had been performed after blocking for 15 minutes and 30 minutes, reduction effect of infarction area was big, and superoxide product, which was measured 30 minutes after reperfusion, was reduced, and 2 days after damage of cerebral ischemia/ reperfusion, it also reduced increase of TUNEL positive cells around ambient ischemia, and also ischemic postconditioning reduced oxidative stress material which was caused during reperfusion and reduced damage by restraining apoptosis [4]. Xing et al. [10] reported when postconditioning, in a way of repeatedly reperfusion for 30 seconds and blockage for 30 seconds in consecutive 6 times after temporary blocking of middle cerebral artery for 60 minutes in rat, was conducted, Bcl-2 which was antiapoptosis protein was increased, and also movement of Bax and cytochrome $\mathrm{C}$ from mitochondrial to cytoplasm was reduced. Consequently, postconditioning is recognized to restrain mechanism of apoptosis of cortical neuronal cell due to damage of ischemia/reperfusion. In this study, Infarction area and edema was measured 24 hours after brain damage in group which was applied by ischemic postconditioning, and when counting number of active cell of caspase- 3 in caudoputamen section and ambient frontoparietal, no significant difference was found in the control group respectively. Therefore, ischemic postconditioning was recognized to have little neuroprotective effects in early brain damage and could not restrain effectively mechanism of Apoptosis. However, depending on model of experimental animals and damage, postconditioning effects varied and exact time and cycle of reperfusion/block in postconditioning to have cerebral protective effect has not clarified yet $[4,10]$. Reperfusion for 30 seconds and then block for 10 seconds in a cycle of 3 times was applied in this study. But, even though same cycle of reperfusion/block with previous methods reported was applied [4], as a method was used in way which middle carotid artery was blocked temporarily not permanently and then reperfused it and on reperfusing middle carotid artery, only one side of common carotid artery not both side carotid artery was tied up and off by forceps, partial movement of blood flow through collateral circulation, which was possible to be existed in circle of Willis or proximal part of middle carotid artery, could not be perfectly controlled. With this reason, more effective ischemia and reperfusion were recognized not to be induced. Zhao [21] reported that to induce ischemic damage on one sided middle carotid artery and treat ischemic postconditioning on both sided common carotid artery and both sided middle carotid artery is difficult to expect cerebral protective effect of ischemic postconditioning due to more severe brain damage than permanent ischemic damage of middle carotid artery. To expect neuroprotective effect by ischemic postconditioning directly after reperfusion, it was important to decide duration time and number of cycle for reperfusion and block respectively, and when reperfusion will be conducted [22]. It was generally known that proper observation period for damage after local cerebral ischemia is 2-24 hours, but, in case of light and temporary local ischemia damage, expression might be delayed because of mechanism of Apoptosis differently from damage of permanent or severe ischemia for above 90 minutes [23]. So, if it will be studied for longer observation period, significant findings can be obtained. In addition, since other paths except caspasedependent path among paths of Apoptosis can affect [24], if research for quantification is carried out side by side to quantify major proteins in caspase-dependent and independent path such as cytochrome $\mathrm{C}$, Bcl-2, and Bax protein and apoptosis inducing factor, relationship with Apoptosis should be more clearly clarified.

It was known that Hsp70 was increased responding to stress such as ischemia [25], acted not only as chaperone but also restrained the course of cell-death such as cell necrosis or Apoptosis and control inflammatory response $[6,26]$. Overexpression of Hsp70 could come into neuroprotective effect in cultured neuronal cell [27], and also could reduce brain damage even in experimental model for stroke of rat [28]. There is little research to report that among cell mechanism to reduce damage due to cerebral ischemia and 
reperfusion, postconditioning was related to expression of Hsp, but there is some research to report that Hsp was increased relating to pharmacological postconditioning and ischemic postconditioning [9,10]. O'sullivan et al. [9] reported that after inducing rat to cerebral infarction and shock, when postconditioning was carried out using diazoxide which was channel opener of mitochondria Kapt, Hsp25 and Hsp70 were increased. Xing et al. [10] reported that after blocking of middle carotid artery of rat, and then ischemic postconditioning was carried out on reperfusion, materials relating to mechanism of Apoptosis and the expression of Hsp70 were measured. As a result, Hsp expression was increased after postconditioning, and ischemic postconditioning restrained Apoptosis. Consequently, it had neuroprotective effect to reduce damage of local cerebral ischemia/reperfusion. But unfortunately in this study, influence of ischemic postconditioning on expression of Hsp70 was not clarified as above. This corresponded in some degree with this study which resulted in that brain damage was not reduced after ischemic postconditioning. And, it also related to result that Apoptosis was not reduced. It can be said that authors' expectation that number of Hsp70 active cell will be increased in group who was treated by ischemic postconditioning is wrong. However, in this study, indirect method which calculated number of Hsp70 active cell was used. Therefore, by applying quantitative method such as Western blot to measure direct activity, it is needed to grasp actually how much extent the expression of Hsp70 was arose.

It was thought that the reason why there was few difference of degree in cerebral infarction between the ischemic postconditioning group and the control group was that there had only marginal influence of ischemic postconditioning on protection of blood vessel in nerves. Damage on permeable barrier of micro vessel was appeared within 1-2 hours after blocking of middle cerebral artery, and then Transudate was arisen and destruction of blood brain barrier was started. Vascular nerve had played important role in ischemic cerebral damage [29]. However, the influence of death of endothelial cell in vascular nerve on cerebral edema due to damage of cerebral ischemia have not been clearly clarified yet, and no study have been done yet about the influence of neuroprotective effect in ischemic postconditioning on structure of vascular nerve. The study about this issue is highly required.

It was thought that the reason why there was no big difference in neurological score was that degree of damage was not big and serious so as to cause functional disability. Neurological test methods, which was used in this study, was well known that it reflected clearly relationship between area of cerebral infarction and functional disability but in case of small infarction area, it had no relationship with neurological deficits [30].

In conclusion, to apply ischemic postconditioning after nerve damage due to temporary local cerebral ischemia/reperfusion in Rat had not improved area of cerebral infarction, reduction of edema, and neurological improvement. Therefore, it can be recognized as having no neuroprotective effect in early damage. Regarding mechanism relating to apoptosis and Hsp70, further study is highly required.

\section{References}

1. Chan PH. Role of oxidants in ischemic brain damage. Stroke 1996; 27: 1124-9.

2. Murry CE, Jennings RB, Reimer KA. Preconditioning with ischemia: a delay of lethal cell injury in ischemic myocardium. Circulation 1986; 74: 1124-36.

3. Zhao ZQ, Corvera JS, Halkos ME, Kerendi F, Wang NP, Guyton RA, et al. Inhibition of myocardial injury by ischemic postconditioning during reperfusion: comparison with ischemic preconditioning. Am J Physiol Heart Circ Physiol 2003; 285: H579-88.

4. Zhao H, Sapolsky RM, Steinberg GK. Interrupting reperfusion as a stroke therapy: ischemic postconditioning reduces infarct size after focal ischemia in rats. J Cereb Blood Flow Metab 2006; 26: 1114-21.

5. Jaattela M. Heat shock proteins as cellular lifeguards. Ann Med 1999; 31: 261-71.

6. Giffard RG, Yenari MA. Many mechanisms for hsp70 protection from cerebral ischemia. J Neurosurg Anesthesiol 2004; 16: 53-61.

7. Massa SM, Swanson RA, Sharp FR. The stress gene response in brain. Cerebrovasc Brain Metab Rev 1996; 8: 95-158.

8. Tsuchiya D, Hong S, Matsumori Y, Shiina H, Kayama T, Swanson RA, et al. Overexpression of rat heat shock protein 70 is associated with reduction of early mitochondrial cytochrome $C$ release and subsequent DNA fragmentation after permanent focal ischemia. J Cereb Blood Flow Metab 2003; 23: 718-27.

9. O'Sullivan JC, Yao XL, Alam H, McCabe JT. Diazoxide, as a postconditioning and delayed preconditioning trigger, increases HSP25 and HSP70 in the central nervous system following combined cerebral stroke and hemorrhagic shock. J Neurotrauma 2007; 24: 532-46.

10. Xing B, Chen H, Zhang M, Zhao D, Jiang R, Liu X, et al. Ischemic postconditioning inhibits apoptosis after focal cerebral ischemia/ reperfusion injury in the rat. Stroke 2008; 39: 2362-9.

11. Longa EZ, Weinstein PR, Carlson S, Cummins R. Reversible middle cerebral artery occlusion without craniectomy in rats. Stroke 1989; 20: 84-91.

12. Bederson JB, Pitts LH, Tsuji M, Nishimura MC, Davis RL, Bartkowski H. Rat middle cerebral artery occlusion: evaluation of the model and development of a neurologic examination. Stroke 1986; 17: 472-6.

13. Choi JM, Shin HK, Kim KY, Lee JH, Hong KW. Neuroprotective effect of cilostazol against focal cerebral ischemia via antiapoptotic action in rats. J Pharmacol Exp Ther 2002; 300: 787-93.

14. Xing B, Chen H, Zhang M, Zhao D, Jiang R, Liu X, et al. Ischemic post-conditioning protects brain and reduces inflammation in a rat model of focal cerebral ischemia/reperfusion. J Neurochem 2008; 105: 1737-45.

15. Kinouchi H, Epstein CJ, Mizui T, Carlson E, Chen SF, Chan PH. 
Attenuation of focal cerebral ischemic injury in transgenic mice overexpressing CuZn superoxide dismutase. Proc Natl Acad Sci U S A 1991; 88: 11158-62.

16. Yamashima T. Implication of cysteine proteases calpain, cathepsin and caspase in ischemic neuronal death of primates. Prog Neurobiol 2000; 62: 273-95.

17. Zhao H, Yenari MA, Cheng D, Sapolsky RM, Steinberg GK. Bcl-2 overexpression protects against neuron loss within the ischemic margin following experimental stroke and inhibits cytochrome c translocation and caspase-3 activity. J Neurochem 2003; 85: 102636.

18. Noshita N, Sugawara T, Hayashi T, Lewen A, Omar G, Chan PH. Copper/zinc superoxide dismutase attenuates neuronal cell death by preventing extracellular signal-regulated kinase activation after transient focal cerebral ischemia in mice. J Neurosci 2002; 22: 7923-30.

19. Shimohata T, Zhao H, Steinberg GK. Epsilon PKC may contribute to the protective effect of hypothermia in a rat focal cerebral ischemia model. Stroke 2007; 38: 375-80.

20. Zhao H, Shimohata T, Wang JQ, Sun G, Schaal DW, Sapolsky RM, et al. Akt contributes to neuroprotection by hypothermia against cerebral ischemia in rats. J Neurosci 2005; 25: 9794-806.

21. Zhao H. The protective effect of ischemic postconditioning against ischemic injury: from the heart to the brain. J Neuroimmune Pharmacol 2007; 2: 313-8.

22. Gao X, Ren C, Zhao H. Protective effects of ischemic postconditioning compared with gradual reperfusion or preconditioning. J Neurosci Res 2008; 86: 2505-11.

23. Du C, Hu R, Csernansky CA, Hsu CY, Choi DW. Very delayed infarction after mild focal cerebral ischemia: a role for apoptosis? J
Cereb Blood Flow Metab 1996; 16: 195-201.

24. Zhan RZ, Wu C, Fujihara H, Taga K, Qi S, Naito M, et al. Both caspase-dependent and caspase-independent pathways may be involved in hippocampal CA1 neuronal death because of loss of cytochrome c From mitochondria in a rat forebrain ischemia model. J Cereb Blood Flow Metab 2001; 21: 529-40.

25. Planas AM, Soriano MA, Estrada A, Sanz O, Martin F, Ferrer I. The heat shock stress response after brain lesions: induction of $72 \mathrm{kDa}$ heat shock protein (cell types involved, axonal transport, transcriptional regulation) and protein synthesis inhibition. Prog Neurobiol 1997; 51: 607-36.

26. Giffard RG, Han RQ, Emery JF, Duan M, Pittet JF. Regulation of apoptotic and inflammatory cell signaling in cerebral ischemia: the complex roles of heat shock protein 70. Anesthesiology 2008; 109: 339-48.

27. Beaucamp N, Harding TC, Geddes BJ, Williams J, Uney JB. Overexpression of hsp70i facilitates reactivation of intracellular proteins in neurones and protects them from denaturing stress. FEBS Lett 1998; 441: 215-9.

28. Kelly S, Zhang ZJ, Zhao H, Xu L, Giffard RG, Sapolsky RM, et al. Gene transfer of HSP72 protects cornu ammonis 1 region of the hippocampus neurons from global ischemia: influence of Bcl-2. Ann Neurol 2002; 52: 160-7.

29. del Zoppo GJ, Mabuchi T. Cerebral microvessel responses to focal ischemia. J Cereb Blood Flow Metab 2003; 23: 879-94.

30. Zausinger S, Hungerhuber E, Baethmann A, Reulen H, SchmidElsaesser R. Neurological impairment in rats after transient middle cerebral artery occlusion: a comparative study under various treatment paradigms. Brain Res 2000; 863: 94-105. 